\title{
EXTENSION PGROUTING A-STAR UNTUK MENAMPILKAN KEMIRINGAN JALAN KENDARAAN ANGKUT DI TAMBANG TERBUKA
}

\author{
Nuri Rahmawati, Agung Budi Cahyono, Yanto Budisusanto \\ Jurusan Teknik Geomatika, FTSP, ITS-Sukolilo, Surabaya, 60111 \\ Email: agungbc@geodesy.its.ac.id, yanto_b@geodesy.its.ac.id
}

\begin{abstract}
Abstrak
Dalam perkembangan Sistem Informasi Geografis (SIG) dapat dijadikan sebagai alat bantu dalam menentukan rute jalur jalan dari suatu lokasi menuju lokasi lain, seperti penentuan rute dengan menggunakan extension pgRouting. Extension pgRouting ini dapat memecahkan masalah dari kelemahan penggambaran, perhitungan, dan penganalisa kemiringan dan jarak jalur jalan kendaraan angkut tambang terbukayang digunakan pada seksi survei tambang (Mine Survey Section) Distrik Anugerah Bara Kaltim Loa Janan (ABKL) PT Pamapersada Nusantara (PAMA). Pada penelitian ini extension pgRouting akan diterapkan untuk menganalisa jalur jalan kendaraan angkut yang lebih otomatis. Metode yang digunakan pada extension pgRouting penelitian ini adalah algoritmaa-star $\left(A^{*}\right)$. Extension pgRouting dapat menampilkan kemiringan dan jarak jalur jalan kendaraan angkut secara otomatis yang memiliki kemiringan diatas $8 \%$ jalur jalan yang dilalui kendaraan angkut. Tetapi pgRouting memiliki kelemahan pada parameter yang digunakan koordinat $X$ dan $Y$ saja, sementara untuk mendapatkan nilai kemiringan jalur jalan kendaraan angkut dibutuhkan parameter koordinat Z. Memodifikasi pgRouting 2D menjadi pgRouting 3D adalah metode yang dapat digunakan untuk memecahkan kelemahan metode extension pgRouting tersebut untuk membantu membaca parameter koordinat Z. Hasil penelitian ini adalah profil melintang rute jalur jalan kendaraan angkut dan update kolom geometri rute jalur kendaraan angkut tiap-tiap jenis kendaraan.
\end{abstract}

Kata Kunci : algoritma A-Star, tambang terbuka, pgRouting,SIG

\section{PENDAHULUAN}

\section{Latar Belakang}

Saat ini telah banyak sistem informasi yang digunakan untuk menunjang dan menyelesaikan suatu permasalahan yang biasanya timbul dalam suatu organisasi, perusahaan, ataupun instansi pemerintahan, salah satunya adalah Sistem Informasi Geografis (SIG). SIG adalah sistem informasi berbasis komputer yang digunakan untuk mengambil, menyimpan, menseleksi, menganalisa, dan menampilkan data geografis [1]. Dalam perkembangan SIG dapat dijadikan sebagai alat bantu dalam menentukan rute jalur jalan dari suatu lokasi menuju lokasi lain, seperti penentuan rute dengan menggunakan extension pgRouting pada perangkat lunak postgreSQL dan postGISyang dapat memecahkan masalah dari kelemahan metode yang digunakan pada seksi survei tambang(Mine Survey Section) Distrik Anugerah Bara Kaltim Loa Janan (ABKL) PT
Pamapersada Nusantara (PAMA).Metode yang digunakan pada seksi survei tambang ini adalah penggambaran jalur jalan kendaraan angkut pada autoCAD dan perhitungan kemiringan jalur jalan kendaraan angkut pada microsoftexcel. Metode penggambaran jalur jalan kendaraan angkut pada autoCAD memiliki kelemahan bahwa pengguna tidak dapat mengetahui jalur jalan yang dilalui tiap-tiap kendaraan angkut yang berbeda. Metode perhitungan kemiringan jalur jalan kendaraan angkut padamicrosoft excel memiliki kelemahan bahwa pengguna harus menyeleksi jalur jalur jalan yang memiliki kemiringan diatas $8 \%$ dan kemudian digambarkan pada autoCAD.

Extension pgRouting menerapkan sistem basis data spasial pada teknologiSIG [2].Tetapi pgRouting memiliki kelemahan pada parameter yang digunakan koordinat $X$ dan $Y$ saja, sementara untuk mendapatkan nilai kemiringan jalur jalan kendaraan angkut dibutuhkan parameter 
koordinat Z. Memodifikasi pgRouting 2D menjadi pgRouting 3D adalah metode yang dapat digunakan untuk memecahkan kelemahan metode extension pgRouting tersebut untuk membantu membaca parameter koordinat $\mathrm{Z}$.

Pada penelitian ini extension pgRouting pada perangkat lunak postgreSQL dan postGIS akan diterapkan untuk menganalisa jalur jalan kendaraan angkut, sehingga hasil yang diperoleh lebih otomatis. Metode yang digunakan pada extension pgRouting penelitian ini adalah algoritmaa-star $\left(A^{*}\right)$.Algoritma $A^{*}$ adalah algoritm BestFirst Search (BSF)dimana nilai sisi yang terkait dengan titikyaitu [3]:

$$
f(n)=g(n)+h(n)
$$

Dimana,

$$
f(n)=\text { nilai sisi }
$$

$g(n)=$ nilai biayadari keadaan awal ke titikn

$h(n)=$ perkiraan nilai heuristikdari titikn ketujuan

Extension pgRouting dapat menampilkan kemiringan jalur jalan kendaraan angkut secara otomatis yang memiliki kemiringan diatas $8 \%$ jalur jalan yang dilalui kendaraan angkut. Analisa kemiringan jalur jalan kendaraan angkut ini digunakan untuk bahan evaluasi perbaikan jalur jalan agar sesuai dengan standardnya yaitu kemiringan kurang dari $8 \%$ (standard dari pabrik kendaraan angkut Komatsu) apabila kemiringan lebih besar dari $8 \%$ akan dilakukan proses penimbunan sesuai dengan volume cross section.

\section{METODOLOGI PENELITIAN}

\section{Data dan Lokasi Penelitian}

Data penelitian yang digunakan adalah data pengukuran koordinat jalur jalan kendaraan angkut, Peta Vektor Kontur Situasi Tambang, dan Peta Hauling Monitoring Tambang Terbuka JPS Distrik Anugerah Bara Kaltim Loa Janan (ABKL) PT Pamapersada Nusantara (PAMA)di Jalan Gerbang Dayaku Desa Bakungan, Kecamatan Loa Janan, Kabupaten Kutai Kartanegara, Kalimantan Timur. Lokasi penelitian dapat dilihat pada Gambar 1 yang dilingkari dengan warna merah.Luas cakupan area tambang terbuka batubaraJPS adalah 459.6065 hektar.Koordinat Loa Janan 116 $49^{\prime}$ BT $117^{\circ} 08^{\prime}$ BT dan $0^{\circ} 34^{\prime} \mathrm{LS}-0^{\circ} 45^{\prime} \mathrm{LS}$.

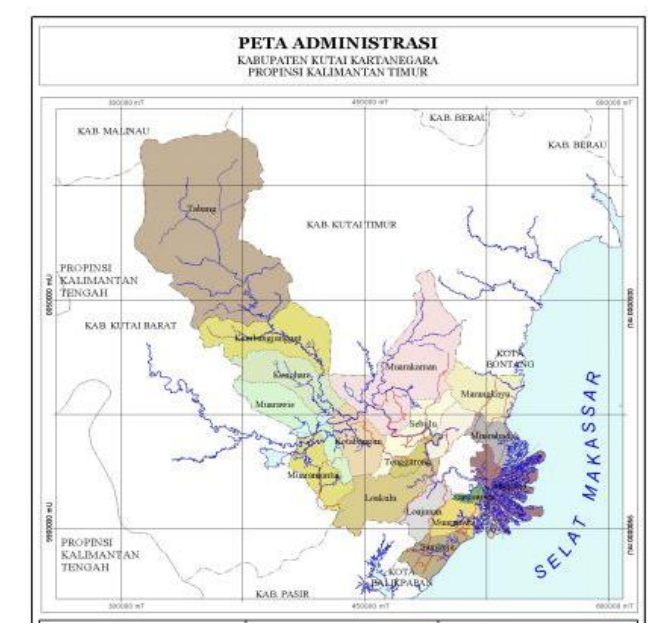

Gambar 1. Lokasi Penelitian (sumber: BAPPEDA Kabupaten Kutai Kartanegara)

\section{Tahapan Pengolahan Data}

Diagram Alir proses Pengolahan Data pada penelitian ini ditunjukkan oleh Gambar2.

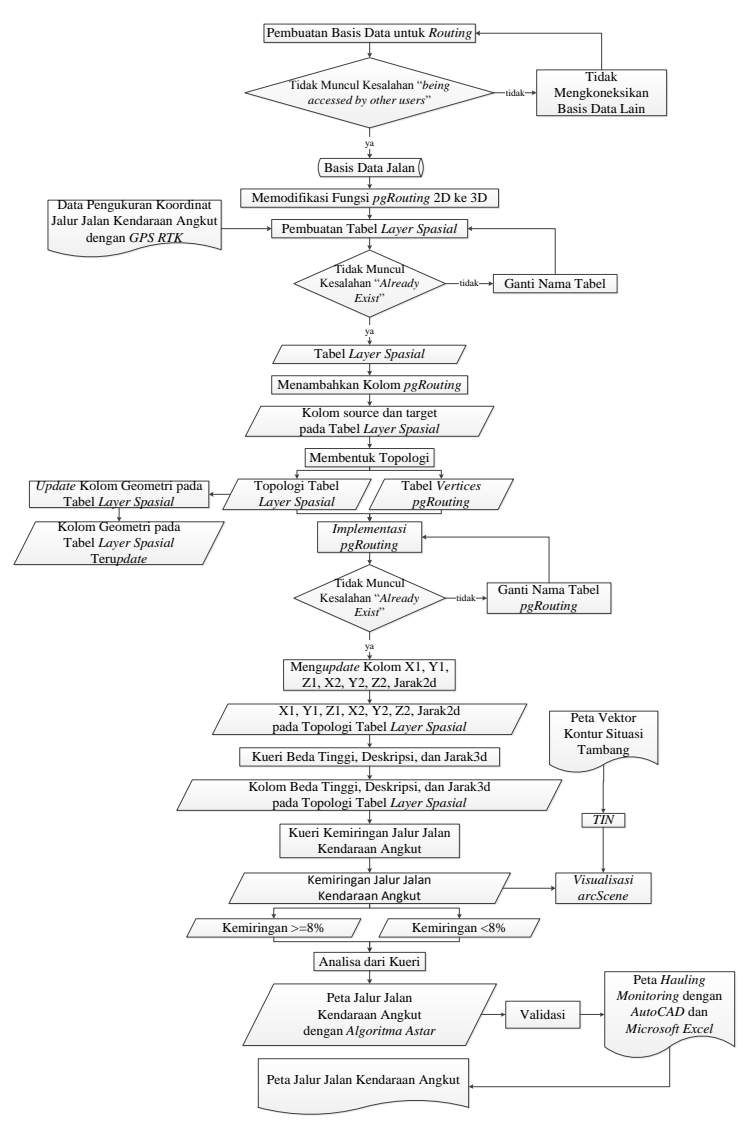

Gambar 2. Diagram Alir Tahapan Penelitian

Penjelasan diagram alir tahapan pengolahan data diatas adalah sebagai berikut:

1) Pembuatan Basis Data untuk Routingdengan membuka aplikasi pgAdmin dan 
mengkoneksikan dengan server PostgreSQL yang bersangkutan dan membuat basis data.

2) Fungsi "assign_vertex_id" dan Fungsi "pgr_createtopology" pada pgRouting dimodifikasi untuk membaca parameter koordinat $Z$ yang telah dibuat.Perubahan yang dilakukan adalah dengan merubah dimensi yang pada awalnya $2 \mathrm{D}$ hanya untuk memproses data koordinat $X Y$ menjadi 3D untuk koordinat $\mathrm{XYZ}$.

3) Pembuatan Tabel Layer Spasialyang bertipe geometri garis dapat dilakukan dengan menggunakan kode SQLCREATE TABLE. Sedangkan untuk kolom obyek spasial geometri garis ke dalam tabel layer spasial dengan menggunakan kode SQLAddGeometryColumn.

4) Menambahkan kolom source dan targetpgRoutingdengan menggunakan kode SQLALTER TABEL.

5) Membentuk Topologi dengan fungsi pgr_createtopology. Fungsi ini digunakan untuk mengisi nilai-nilai atribut "source" [nomor pengenal titik/vertex/node awal segmen garis yang bersangkutan] dan "target" [nomor pengenal titik/vertex/node akhir segmen garis yang bersangkutan] dengan nilai-nilai bilangan bulat nomor pengenal pada tabellayer spasial yang akan diperhitungkan di dalam operasi routing.

6) Implementasi pgRouting algoritma a-star dengan menggunakan fungsi pgr_astar.

7) Mengupdate kolom $\mathrm{X} 1, \mathrm{Y} 1, \mathrm{Z} 1, \mathrm{X} 2, \mathrm{Y} 2, \mathrm{Z2}$, Jarak2d dengan menambahkan kolom $X 1, Y 1$, $\mathrm{Z1}, \mathrm{X} 2, \mathrm{Y} 2, \mathrm{Z2}$, Jarak2d dan pengisian nilai-nilai kolom tersebut menggunakan kode SQL ALTER TABEL dan UPDATE.

8) Penentuan beda tinggi dan deskripsi dengan menggunakan kuerididapatkan analisis berupa koordinat Z titikawal dan titikakhir dari kolom obyek spasial. Hasil kueriini akan mengisi kolom beda_tinggi dan deskripsi dari titikawal dan titikakhir pada tabel layer spasial. Apabila hasil kueri beda tinggi positif (nilai z2 lebih besar dari nilai z1) menunjukkan bahwa deskripsi jalan itu naik sedangkan apabila hasil kueri beda tinggi negatif (nilai z1 lebih besar dari nilai z2) menunjukkan bahwa deskripsi jalan itu turun. Beda tinggi jalur jalan kendaraan angkut didapatkan dari perhitungan:

$$
\Delta z=z_{2}-z_{1}
$$

Dimana,

$\Delta z=$ beda tinggi

$z_{2}=$ tinggi titik akhir

$z_{1}=$ tinggi titik awal

9) Penentuan jarak3d dengan memodifikasi fungsi getdistance $2 D$ menjadi fungsi getdistance 3Dpada postgreSQLdidapatkan kuerianalisis berupa koordinat XYZ titik awal dan titik akhir dari kolom obyek spasial. Hasil kueriini akan mengisi kolom jarak3d jalur jalan kendaraan angkut dari titik awal hingga titik akhir pada tabel geometri jln3d. Adapun perhitungan jarak3d sebagai berikut:

$\sqrt{{\left(k_{2}{ }^{2}-x_{1}{ }^{2}+{\left(k_{2}\right.}^{2}-y_{1}{ }^{2}+\left(_{2}{ }^{2}-z_{1}{ }^{2}\right.\right.}}$

Dimana,

$x_{1}=$ koordinat $\mathrm{x}$ titik awal

$x_{2}=$ koordinat $\mathrm{x}$ titik akhir

$y_{1}=$ koordinat $\mathrm{y}$ titik awal

$y_{2} \quad=$ koordinat $\mathrm{y}$ titik akhir

$z_{1}=$ koordinat $z$ titik awal

$z_{2}=$ koordinat $z$ titik akhir

10) Dari fungsi pgRouting didapatkan kuerianalisis jalur berupa id, node, edge, dan cost. Hasil kueritersebut kemudian akan menjadi variable untuk mendapatkan atribut kemiringan jalur jalan kendaraan angkut masing node awal dan node akhir dari tabel layer_routing. Kemiringan jalur jalan kendaraan angkut didapatkan dari perhitungan: [4]

$$
\text { kemiringan }=\frac{\text { beda_tinggi }}{\text { jarak }} \times 100 \%
$$

Dimana,

$$
\begin{aligned}
\text { beda_tinggi } & =\text { selisih tinggi }(\mathrm{Z}) \text { antara titik } \\
& \text { akhir dan titik awal }(\mathrm{m}) \\
\text { jarak } & =\text { jarak antara dua titik }(\mathrm{m})
\end{aligned}
$$

11) Pembuatan TIN

TIN dapat dibentuk dengan menggunakan data ketinggian peta vektor kontur situasi pitshapefile dengan menggunakan aplikasi create TIN pada arcscene.

12) Visualisasi Arcscene

Kemudian hasil kueri dilakukan proses visualisasi dengan arcscene dan digabungkan dengan data TIN. 
13) Update Kolom Geometri pada Tabel Layer Spasialdengan menggunakan kode SQL UPDATE.

14) Peta Jalur Jalan Kendaraan Angkut divalidasi dengan Peta Hauling Monitoring menggunakan prosentase.

15) Pembuatan Peta Jalur Jalan Kendaraan Angkut.

\section{HASIL DAN ANALISA}

Pada Gambar 3 menunjukkan jalur jalan kendaraan angkut jenis DT449 bahwa elevasi akan semakin tinggi ketika Front Loading 449 menuju Dumping Point 449.

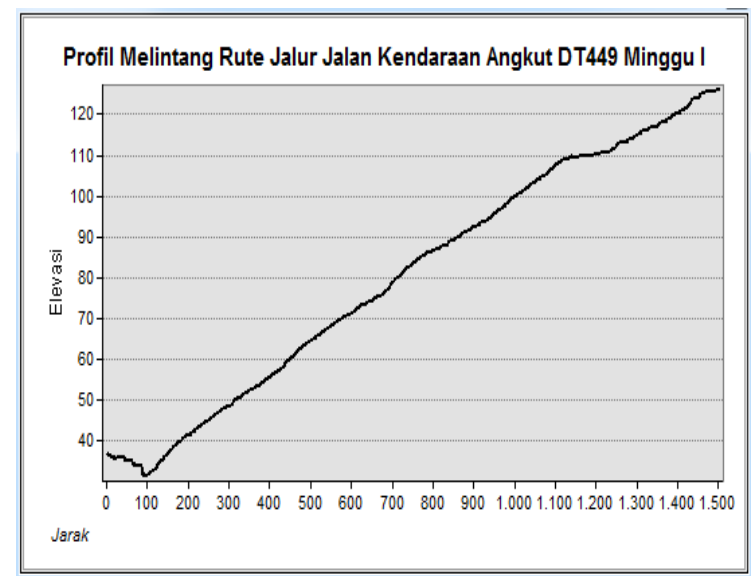

Gambar 3. Profil Melintang Rute Jalur Jalan Kendaraan Angkut (Front Loading 449 menuju Dumping Point 449)

Dengan menggunakan fungsi pada SQL di postgreSQL kolom geometri dapat diupdate dari waktu ke waktu. Proses update ini dapat digunakan untuk mengupdate data titik awal pada area pengambilan tanah (front loading) dan titik akhir pembuangan tanah (dumping point) dan sebaliknya dapat dilihat pada Table 1.
Tabel 1. Hasil Update Kolom Geometri

\begin{tabular}{|c|c|c|}
\hline $\begin{array}{l}\text { Jenis } \\
\text { Kendaraan } \\
\text { dan Lokasi }\end{array}$ & $\begin{array}{l}\text { Minggu } \\
\text { ke- }\end{array}$ & $\begin{array}{c}\text { Koordinat } \\
(X ; Y ; Z)\end{array}$ \\
\hline \multirow{2}{*}{$\begin{array}{c}\text { DT1075 } \\
\text { lokasi } \\
\text { pengambilan } \\
\text { tanah (Front } \\
\text { Loading) }\end{array}$} & $\begin{array}{c}\text { Minggu } \\
\text { I }\end{array}$ & $\begin{array}{c}505286,3130 ; \\
9923538,1340 ; \\
66,9040)\end{array}$ \\
\hline & $\begin{array}{l}\text { Minggu } \\
\text { II }\end{array}$ & $\begin{array}{c}505309,1940 ; \\
9923561,2490 ; \\
62,0600)\end{array}$ \\
\hline \multirow{2}{*}{$\begin{array}{c}\text { DT1075 } \\
\text { lokasi } \\
\text { pembuangan } \\
\text { tanah } \\
\text { (Dumping } \\
\text { Point) }\end{array}$} & $\begin{array}{c}\text { Minggu } \\
\text { I }\end{array}$ & $\begin{array}{c}(505982,4870 ; \\
9924878,9410 ; \\
116,9240) \\
\end{array}$ \\
\hline & $\begin{array}{l}\text { Minggu } \\
\text { II }\end{array}$ & $\begin{array}{c}(505999,3660 ; \\
9924858,8200 ; \\
119,0070) \\
\end{array}$ \\
\hline \multirow{2}{*}{$\begin{array}{c}\text { DT1075 } \\
\text { lokasi } \\
\text { pengambilan } \\
\text { tanah (Front } \\
\text { Loading) }\end{array}$} & $\begin{array}{c}\text { Minggu } \\
\text { II }\end{array}$ & $\begin{array}{c}(505309,1940 ; \\
9923561,2490 ; \\
62,0600)\end{array}$ \\
\hline & $\begin{array}{l}\text { Minggu } \\
\text { III }\end{array}$ & $\begin{array}{c}\text { (505216,3080; } \\
\text { 9923542,0950; } \\
\text { 5) nn8n) }\end{array}$ \\
\hline
\end{tabular}

Perubahan layer spasial titik area pengambilan (front loading) dan pembuangan (dumping point) dapat dilihat pada Gambar 4- 6. Pada gambar menunjukkan bahwa:

- Bendera warna biru: titik area pengambilan (front loading) dan pembuangan (dumping point) minggu ke 1

- Berndera warna merah: titik area pengambilan (front loading) dan pembuangan (dumping point) minggu ke 2

- Bendera warna kuning: titik area pengambilan (front loading) dan pembuangan (dumping point) minggu ke 3

- Garis warna biru: jalur jalan kendaraan angkut minggu ke 1

- Garis warna merah: jalur jalan kendaraan angkut minggu ke 2

- Garis warna kuning: jalur jalan kendaraan angkut minggu ke 3 


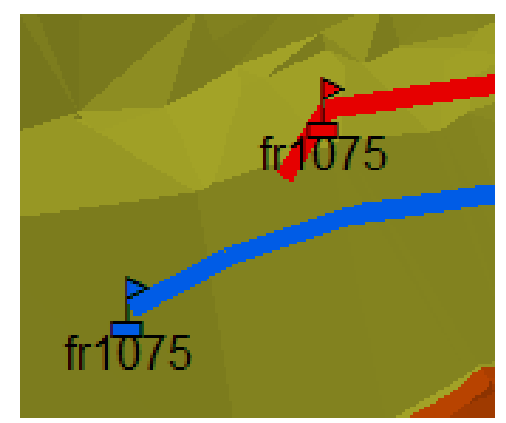

Gambar 4. Perubahan Titik Area Pengambilan Tanah (Front Loading) Minggu ke 1 dan Minggu ke 2 Jenis Kendaraan DT1075

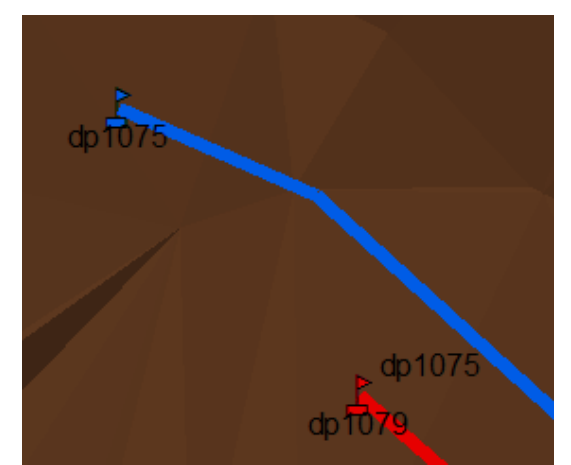

Gambar 5. Perubahan Titik Area Pembuangan Tanah (Dumping Point) Minggu ke 1 dan Minggu ke 2 Jenis Kendaraan DT1075

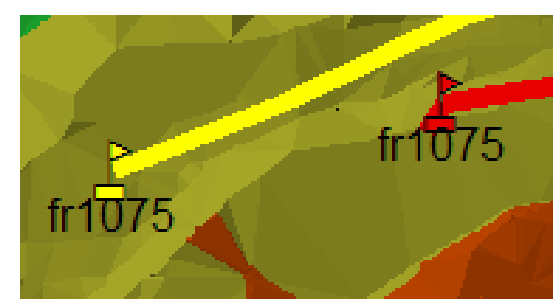

Gambar 6. Perubahan Titik Area

Pengambilan Tanah (Front Loading) Minggu

ke 2 dan Minggu ke 3 Jenis Kendaraan DT1075

Dari hasil pengolahan jalur jalan kendaraan angkut dengan menggunakan pgRouting didapatkan prosentase kemiringan masing-masing rute yang ditampilkan pada Tabel 2 .
Tabel 2. Prosentase Kemiringan $>=8 \%$

\begin{tabular}{|c|c|c|c|c|}
\hline \multirow{2}{*}{$\begin{array}{l}\text { Minggu } \\
\text { ke- }\end{array}$} & \multirow{2}{*}{$\begin{array}{c}\text { Jenis } \\
\text { Kendaraa } \\
n\end{array}$} & \multicolumn{2}{|c|}{$\begin{array}{l}\text { Nilai Prosentase } \\
\text { Kemiringan }>=8\end{array}$} & \multirow{2}{*}{$\begin{array}{c}\text { Rata-rata } \\
\text { Prosenta } \\
\text { se } \\
\text { Kemiring } \\
\text { an }>=8\end{array}$} \\
\hline & & $\begin{array}{c}\text { Terend } \\
\text { ah }\end{array}$ & $\begin{array}{c}\text { Terting } \\
\text { gi }\end{array}$ & \\
\hline \multirow{3}{*}{$\underset{\mathrm{I}}{\text { Minggu }}$} & DT449 & 8,0 & 10,1 & 9,4 \\
\hline & DT1075 & 8,0 & 12,3 & 9,7 \\
\hline & DT1079 & 8,3 & 16,9 & 9,7 \\
\hline \multirow{7}{*}{$\begin{array}{c}\text { Minggu } \\
\text { II }\end{array}$} & DT1045 & 8,1 & 15,5 & 9,8 \\
\hline & DT1075 & 8,1 & 15,7 & 9,8 \\
\hline & DT1079 & 8,1 & 15,7 & 9,9 \\
\hline & DT449 & 8,1 & 11,0 & 9,2 \\
\hline & DT1050 & 8,1 & 18,7 & 10,1 \\
\hline & DT1062 & 8,1 & 18,7 & 10,3 \\
\hline & DT1044 & 8,1 & 12,8 & 9,6 \\
\hline \multirow{3}{*}{$\begin{array}{c}\text { Minggu } \\
\text { III }\end{array}$} & DT1075 & 8,1 & 12,1 & 9,6 \\
\hline & DT1062 & 8,2 & 18,7 & 10,6 \\
\hline & DT1044 & 8,2 & 12,4 & 9,4 \\
\hline
\end{tabular}

Berdasarkan Tabel 2 dapat dilihat bahwa:

- Rata-rata prosentase kemiringan tertinggi untuk kondisi jalan yang memiliki kemiringan lebih dari $8 \%$ terjadi pada minggu ke 3 dengan ratarata prosentase sebesar $10,6 \%$.

- Rata-rata prosentase kemiringan terendah untuk kondisi jalan yang memiliki kemiringan lebih dari $8 \%$ terjadi pada minggu ke 3 dengan rata-rata prosentase sebesar $8,8 \%$.

\section{PENUTUP}

\section{Kesimpulan}

Kesimpulan yang didapatkan dalam penelitian ini adalah sebagai berikut:

1. Berdasarkan analisa kemiringan jalur jalan kendaraan angkut didapatkan nilai rata-rata kemirigan paling rendah pada periode 3 minggu sebesar $8,8 \%$ sedangkan nilai rata-rata kemirigan paling tinggi pada periode 3 minggu sebesar $10,6 \%$.

2. Berdasarkan profil melintang rute jalur jalan kendaraan angkut DT449 Minggu 1 memiliki elevasi terendah 0 meter dan elevasi tertinggi 130 meter.

3. Lokasi titik area jalur jalan kendaraan angkut yang tidak mengalami update terdapat pada titik area pembuangan tanah (dumping point) jenis kendaraan DT1075, DT1062, dan DT1044 pada minggu ke II dan minggu ke III. 


\section{DAFTAR PUSTAKA}

Kang-Tsu Chang. 2008. Introduction Geographic Information Systems Fourth Edition. New York: McGraw-Hill Education.

Prahasta, E. 2012. Tutorial PostgreSQL, PostGIS, dan pgRouting untuk Geodesi \& Informatika serta IImu Kebumian Lainnya, seperti: Geologi, Geofisika, Geografi, Metereologi, Oseanografi, Pertambangan, dan Perminyakan. Bandung: Informatika.

Munir, R. 2003. Matematika Diskrit Edisi Ketiga. ITB: Teknik Informatika.

Rooij, P.V. 2010. Manual 6: Buku Pegangan. <URL http://www.ilo.org/wcmsp5/groups/public/ ---asia/---ro-bangkok/---ilo-

jakarta/documents/publication/wcms 1714 28.pdf> dikunjungi pada tanggal 27 Maret 2014 pukul 14.45 BBWI. 